\title{
Chronic Granulomatous Disease: Quantitative Clinicopathological Relationships
}

\author{
EILEEN N. THOMPSON and J. F. SOOTHILL \\ From the Department of Immunology, Institute of Child Health, and The Hospital for Sick Children, London
}

\begin{abstract}
Thompson, Eileen N., and Soothill, J. F. (1970). Archives of Disease in Childhood, 45, 24. Chronic granulomatous disease: quantitative clinicopathological relationships. 10 children with chronic granulomatous disease are described. Though the clinical features were typical, a wide range of clinical severity was noted. A significant correlation between the severity of the syndrome and the qualitative nitro-blue tetrazolium results was found.

Facial rashes (4) and polyarthritis (1) were noted in female presumed heterozygotes, the incidence of which was also related to the nitro-blue tetrazolium test results. A father and a paternal great uncle died of leukaemia. The possible aetiological relation between these and the partial leucocyte abnormality is discussed.

Three children were treated with busulphan, in order to induce neutropenia, to expose the ingested organisms to humoral bactericidal mechanisms, and to antibiotics. There was evidence suggestive of benefit in one of them.
\end{abstract}

In 1957 attention was drawn to a new syndrome in male children referred to as fatal granulomatous disease of childhood (Berendes, Bridges, and Good, 1957; Bridges, Berendes, and Good, 1959). The characteristic features were recurrent suppurative lymphadenopathy, pulmonary infiltrations, visceral abscesses, and death before the 6th year of life. Anaemia, leucocytosis, increased serum immunoglobulins, and pulmonary granulomatosis lesions were also noted. Since then further cases have been described confirming the clinical and histological features (Landing and Shirkey, 1957; Carson et al., 1965; Johnston and McMurry, 1967).

The polymorphonuclear leucocytes in these patients have diminished capacity to kill certain bacteria (Holmes et al., 1966; Quie et al., 1967) so that the polymorphs fail in vitro to kill the organisms that are also the most troublesome clinicallycoagulase-positive staphylococci and many Gramnegative bacteria. Baehner and Nathan (1967) reported a deficiency of reduced nicotinamide adenine dinucleotide oxidase in the leucocytes of these patients, which can be recognized by failure to reduce nitro-blue tetrazolium during phagocytosis. This provides both a qualitative test (Windhorst, Holmes, and Good, 1967) and a quantitative measurement of functional abnormality (Baehner and Nathan, 1968).

It has been suggested from the distribution in

Received 24 June 1969 families, with full expression of the disease in magess familial occurrence in brothers and male cousi is and sparing of parents with partial defect in mothess? that the disease is inherited as an $\mathrm{X}$-lin characteristic (Windhorst et al., 1967; 1968) However, recently there have been reports of 8 symptomatically affected females showing the samo functional abnormality (Baehner and Nathan 1968; Quie et al., 1968), suggesting that anothe? mode of inheritance is possible, and we have reported elsewhere that existing data are compatible with a sex-modified autosomal recessive inheritance (Chandra, Cope, and Soothill, 1969a).

We report our findings in 10 boys who were diagnosed by means of the nitro-blue tetrazolium? (NBT) reaction. Significant quantitative heterog geneity of the disease was shown in both homo 3 zygous and heterozygous subjects, and this is discussed in terms of possible lines of treatment? Manifestations in relatives are discussed.

\section{Methods}

The qualitative NBT test was done by the method described by Windhorst et al. (1967). Cells from \& healthy control were cultured in paraliel with all the samples. Three slides were prepared from each sample coded and mixed before counting. 200 cells containin phagocytosed latex particles were counted on each slide, spanning fields from the edge of the film in $\vec{a}$ stepwise fashion, and the percentage containing blue 
dye recorded. The mean values from the three slides from each sample were calculated after breaking the code. Each subject was studied at least twice and mean values are given in Table I and Fig. 1. The diagnosis of the patients was based on this test.

The quantitative NBT test was that of Baehner and Nathan (1968).

Immunoglobulins were estimated by the gel diffusion method (Mancini, Carbonara, and Heremans, 1965) and results expressed as a percentage of the Proposed British Research Standard for Human Immunoglobulin $\mathrm{G}, \mathrm{A}$, and $\mathrm{M}$.

\section{Clinical Findings}

A brief clinical description of the 10 affected boys is given here (with age at diagnosis) and in Table I.

Case 1 (1 year). This child thrived well until 3 months of age. After this he developed two episodes of suppurative cervical lymphadenopathy, and a liver abscess at 6 months of age. Staph. aureus was cultured from each of these lesions. Over the next few months his general condition deteriorated. He developed three further chronic suppurative lymph node abscesses, ischiorectal abscess, osteomyelitis in the left tibia, left ulnar and right frontal bone, all requiring repeated incision. Esch. coli was obtained on culture of the pus. Extensive pulmonary infiltration on $x$-ray developed and progressed despite large doses of antibiotics. Busulphan treatment was given (see later). $\mathrm{He}$ died at 13 months.

Case 2 (5 years). The fourth of 4 children, of whom one brother and one sister are healthy; a brother died at 7 weeks of age from septicaemia. He thrived well for the first $\mathbf{4}$ months of life until the onset of an inguinal abscess. This was followed by two bouts of pneumonia, osteomyelitis of the os calcis, olecranon, tibia, and ribs, and ischiorectal abscess. Initially each episode cleared slowly and he remained symptom free from 3-4 months. Since the age of 18 months one episode has followed another in quick succession, with only partial clearing despite incision and almost constant antibiotic therapy. Organisms grown from the pus were Staph. aureus, klebsiella species, proteus species, Esch. coli, and Aspergillus nidulans, and an acid-fast organism was seen in the pus on one occasion, though culture was negative. Cutaneous testing showed delayed hypersensitivity to Candida albicans and to the avian Mycobacterium tuberculosis, but negative to the

\section{TABLE I}

Results in Patients with Chronic Granulomatous Disease

\begin{tabular}{|c|c|c|c|c|c|c|c|c|c|c|c|c|c|c|}
\hline \multirow{3}{*}{$\begin{array}{l}\text { Case } \\
\text { No. }\end{array}$} & \multirow{3}{*}{$\begin{array}{c}\text { Age at } \\
\text { Diagnosis } \\
\text { (yr.) }\end{array}$} & \multirow{2}{*}{\multicolumn{2}{|c|}{$\begin{array}{c}\text { Sibs } \\
\text { Affected/ } \\
\text { Unaffected }\end{array}$}} & \multicolumn{3}{|c|}{$\begin{array}{l}\text { Age (yr.) at Onset } \\
\text { of Infections }\end{array}$} & \multicolumn{2}{|c|}{ Centiles } & \multirow{3}{*}{$\begin{array}{c}\text { Order } \\
\text { of } \\
\text { Clinical } \\
\text { Severity }\end{array}$} & \multirow{3}{*}{$\begin{array}{l}\text { Qualitative } \\
\text { NBT } \\
\text { (\% of cells } \\
\text { stained) }\end{array}$} & \multirow{2}{*}{\multicolumn{3}{|c|}{$\begin{array}{l}\text { Serum Immuno- } \\
\text { globulins (\% of } \\
\text { MRC Standard } \\
\text { serum) }\end{array}$}} & \multirow{3}{*}{$\begin{array}{l}\text { Organisms } \\
\text { Cultured from } \\
\text { Pus }\end{array}$} \\
\hline & & & & \multirow[b]{2}{*}{ Skin } & \multirow{2}{*}{$\begin{array}{l}\text { Lymph } \\
\text { Nodes }\end{array}$} & \multirow{2}{*}{$\begin{array}{l}\text { Vis- } \\
\text { ceral } \\
\text { Ab- } \\
\text { scess }\end{array}$} & \multirow{2}{*}{ Height } & \multirow{2}{*}{ Weight } & & & & & & \\
\hline & & Males & $\begin{array}{c}\mathrm{Fe}- \\
\text { males }\end{array}$ & & & & & & & & $\mathrm{IgG}$ & $\operatorname{IgA}$ & $\operatorname{Ig} M$ & \\
\hline 1 & 1 & $0 / 0$ & $0 / 0$ & - & $3 / 12$ & $6 / 12$ & 1 & 1 & 1 & 0 & 400 & 360 & 248 & $\begin{array}{l}\text { Staph. aureus, } \\
\text { Esch. coli, } \\
\text { S. marcescens }\end{array}$ \\
\hline 2 & 5 & $1 / 1$ & $0 / 1$ & $4 / 12$ & $4 / 12$ & $9 / 12$ & $<1$ & $<1$ & 2 & 0 & 192 & 150 & 75 & $\begin{array}{l}\text { Staph. aureus, } \\
\text { Esch. coli, } \\
\text { klebsiella, } \\
\text { proteus, } \\
\text { Aspergillus } \\
\text { nidulans }\end{array}$ \\
\hline 3 & 3 & $1 / 0$ & $0 / 0$ & $6 / 12$ & 1 & 2 & 75 & 75 & 4 & 0 & 200 & 300 & 250 & $\begin{array}{l}\text { Staph. aureus, } \\
\text { Esch. coli }\end{array}$ \\
\hline 4 & 2 & $0 / 1$ & $0 / 0$ & & $6 ; 12$ & 2 & 10 & 10 & 6 & 0.4 & 100 & 40 & 112 & $\begin{array}{l}\text { Pseudomonas } \\
\text { pseudomallei }\end{array}$ \\
\hline 5 & 67 & $0 / 0$ & $0 / 1$ & $2 / 52$ & $1 \frac{1}{2}$ & $1 \frac{1}{2}$ & 3 & 1 & 3 & $0 \cdot 1$ & 256 & 300 & 75 & $\begin{array}{l}\text { Staph. aureus, } \\
\text { Esch. coli, } \\
\text { Candida } \\
\text { albicans }\end{array}$ \\
\hline 6 & $7)$ & & & & $1 \frac{1}{2}$ & & 3 & 3 & 7 & $1 \cdot 2$ & 256 & $\begin{array}{l}125 \\
464\end{array}$ & 100 & Staph. aureus \\
\hline 7 & 47 & $0 / 0$ & $0 / 1$ & $1 \frac{1}{2}$ & & 2 & 50 & 50 & 5 & $0 \cdot 7$ & 250 & 124 & 160 & $\begin{array}{l}\text { Staph. aureus*, } \\
\text { Esch. coli, } \\
\text { klebsiella }\end{array}$ \\
\hline $\begin{array}{l}8 \\
9\end{array}$ & $\begin{array}{l}11 \\
15\end{array}$ & $1 / 0$ & $1 / 0$ & 1 & $\begin{array}{l}3 \\
6\end{array}$ & 11 & $\begin{array}{r}25 \\
1\end{array}$ & $\begin{array}{r}25 \\
1\end{array}$ & $\begin{array}{r}10 \\
8\end{array}$ & $\begin{array}{l}0 \cdot 7 \\
3 \cdot 5\end{array}$ & $\begin{array}{l}156 \\
280\end{array}$ & $\begin{array}{l}268 \\
112\end{array}$ & $\begin{array}{l}180 \\
200\end{array}$ & $\begin{array}{l}\text { Staph. aureus } \\
\text { Staph. aureus, } \\
\text { Aspergillus }\end{array}$ \\
\hline 10 & 13 & $0 / 0$ & $0 / 1$ & $1 \frac{1}{2}$ & 5 & 5 & 25 & 25 & 9 & $5 \cdot 3$ & 200 & 240 & 180 & $\begin{array}{l}\text { Staph. aureus, } \\
\text { Actinomyces } \\
\text { israelii }\end{array}$ \\
\hline
\end{tabular}


human. There has been marked failure to thrive, and his growth has been grossly retarded with anaemia and leucocytosis for 3 years. Studies of this patient and his family have been reported separately (Thompson et al., 1969).

Case 3 (3 years). He is the second son of healthy parents. His brother died at 14 months of age from gastro-enteritis, having had a chronic suppurative

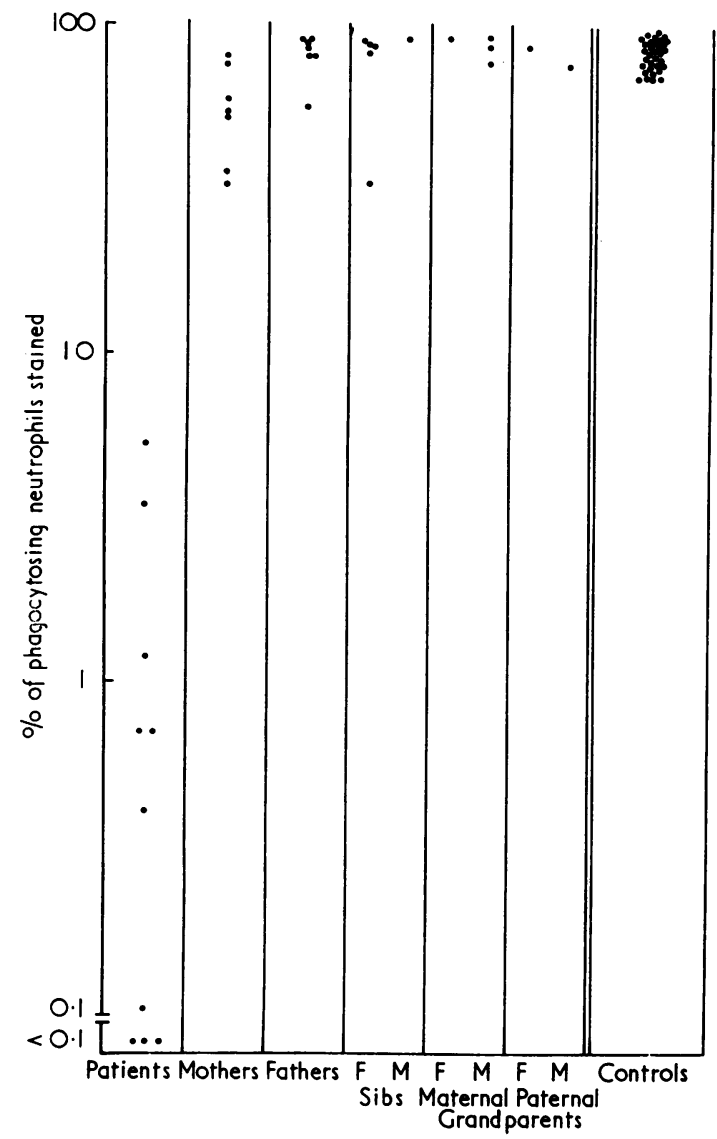

FIG. 1.-Results of qualitative NBT test on controls, patients with chronic granulomatous disease, their parents, grandparents, and sibs.

cervical abscess at 8 months of age. The patient had been well until 6 months of age when he developed repeated pustular skin rashes particularly on the face, neck, hands, and trunk. At 13 months he developed a cervical abscess, followed by 30 separate episodes over the next 2 years. At 2 years of age he had a liver abscess, followed by a lung abscess and empyema. Each lesion had required surgical drainage; healing had been slow, with a tendency to sinus formation. The organism cultured from his pus was usually Staph. aureus; on one occasion an acid-fast organism was seen, but cultufe was negative. He gave a severe delayed hypersens? tivity reaction to avian tuberculin but was negati to human tuberculin.

Case 4 (2 years). This dizygotic twin, birthweigft 2125g., was born to a German mother and Englisf father in Singapore. He developed a cervical abscess at 18 months, with a granulomatous histological reactio but sterile culture, and antituberculous treatment was given. At 2 years, persistent pyrexia and abdoming pain developed, but at laparotomy no abnormality was found. He continued to have repeated fevers ant developed osteomyelitis of fingers and toes, and he failed to thrive. Pseudomonas pseudomallei was cultures from the bone lesions and throat. Chloramphenicof and kanamycin were given, intravenously for 3 weeks and intramuscularly for 4 weeks, and there was a marked clinical improvement; in spite of continued oral sut phadimidine the radiological bone lesions persist.

Case 5 (6 years)^. He had recurrent pustular skif eruptions in the first year of life, and pneumonia $\&$ 6 months. At 16 months of age he became acutely ill with osteomyelitis in the thumb, inguinal and cervical abscespr ses, and septicaemia; the illness lasted 6 months. further cervical abscess occurred at $2 \frac{1}{2}$ years, an pneumonia at 4 years, after which extensive bilatera pulmonary infiltration has remained. Lung biopsy showed a granulomatosis process, containing Can albicans spores. At 6 years he developed a chrente urinary infection; Esch. coli and Candida albigands were obtained on repeated urine culture. IVP showe? mild bilateral hydronephrosis with a contracted bladde He had repeated episodes of unexplained heart failure.

Case 6 (7 years)*. Older brother of Case 5. The? sister is healthy. His illness has been milder that that of his brother, with 5 episodes of cervical abscess from the age of 18 months, and one ischiorectal abscess Each lesion settled readily with antibiotics and drainage sinus formation was not a feature. His illness has been episodic with periods of remission of 6 to 9 months

Case 7 (4 years). Third-born with an affected brother (Case 8) and a normal sister. At 18 months his developed infected eczemoid dermatitis of face, neck? and trunk, which has healed slowly with residual scarring. At 3 years of age he developed a liver abscess (Staph aureus was grown from the pus). Healing was slows with persistent sinus formation for 6 months in spite of antibiotic treatment. After this he was well for 9 month apart from recurrent skin eruptions particularly aroun ${ }^{\circ}$ his eyes and external nares.

Case 8 (11 years). He is the only brother of Case Apart from recurrent pustular skin sepsis for the firs year of life and a solitary groin abscess at 3 years, he was well until 10 years of age when he had pneumoniळ

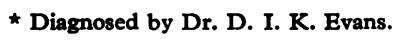


twice which resolved slowly but completely. The illness was accompanied by marked toxicity and high fever; 8 blood cultures were negative.

Case 9 (15 years). He is the third of 3 children, whose father died of leukaemia at 53 years. His brother died at $2 \frac{1}{2}$ years of age after a series of infections involving skin, lymph nodes, liver, and bone from the age of 1 year. His sister aged 20 years is well apart from pustular skin eruptions and a persistent raised rash on the ankles and dorsum of the feet. The patient was well though below the 3rd centile in height and weight, until the age of $6 \frac{1}{5}$ years, when an exploratory operation for suspected right inguinal hernia was followed by a chronic sinus. Histological examination showed granuloma formation. Hepatosplenomegaly, chronic skin infection around the external nares, and extensive bilateral pulmonary infiltration on $x$-ray were noted. Barium swallow showed dilatation, irregular peristalsis, and delayed emptying of the oesophagus. IVP showed normal renal size but bilateral hydronephrosis with dilatation of the ureters to the pelvic brim. He later developed further cervical abscesses and a liver abscess. Histological appearances of the liver at this time showed granuloma formation. After prolonged therapy with antituberculous drugs he slowly recovered after a year, and remained fairly well for the following 7 years, apart from a cervical abscess at $11 \frac{1}{2}$ years of age. At 14 years he developed osteomyelitis in the left tarsal bone (Aspergillus fumigatus obtained on culture). PAS and INAH have been given continuously over the past 7 years. This patient was described by Evans (1962).

Case 10 (13 years). This boy, whose parents and only sister are well, was well until 18 months of age when he developed an indolent ulcer on the right cheek which settled slowly with antibiotics. At 5 years a cervical abscess and osteomyelitis of the right thumb developed. This was followed by suppurative mesenteric nodes, and by subphrenic and liver abscesses. There was granuloma formation on histological examination of the liver and lymph nodes. He was treated with PAS and INAH for 2 years, and after a severe illness lasting 9 months he slowly improved and remained fairly well for 2 years. This was then followed by 2 further cervical abscesses, pneumonia, lung abscess, and osteomyelitis of a rib. Culture of the pus grew Staph. aureus and Actinomyces israelii. Slow clinical improvement followed therapy with antibiotics, though the chest $x$-ray changes persisted. At the age of 11 years, 3 further cervical abscesses occurred in quick succession, which healed slowly despite incision and antibiotic therapy, but since then he has been well with no further infectious episodes, though pulmonary infiltration and hepatosplenomegaly remain.

\section{Results}

The results of the qualitative NBT test, on which the selection of patients was made, are shown in Table I and Fig. 1.
All had normochromic, normocytic anaemia, and polymorphonuclear leucocytosis at the time of infection, but in those with a long remission, counts fell to normal between the infective periods. In 9 of the 10 patients serum immunoglobulin levels were increased. All had been immunized previously with DPT and poliomyelitis antigens. In 3, adequate antibody levels were found before and after a subsequent booster injection of DPT. Lymphocyte transformation with phytohaemagglutinin was normal in the 3 tested, indicating that specific cellular immunity mechanisms were normal. Cutaneous delayed type hypersensitivity was elicited to Candida albicans in 2 and to avian tuberculin in 2 others.

Five were generally stunted and underweight, 3 of whom had had severe and persistent symptoms for months (Table I). 4 were above the 25th centile for height and weight, in spite of frequent infections.

Heterogeneity of clinical expression was noted not only as regards age of onset of symptoms but also in persistence and frequency of the infections. In 2 patients symptoms were continuous for months. 3 had short periods of remission, and in 5, periods of remission during which relatively good health was experienced, ranged from 18 months to 9 years. The patients were ranked in order of clinical severity on this criterion. This was done before the numerical results of the NBT tests were obtained. Statistical analysis of this grading and the NBT results showed a significant correlation ( $p<0.02$ Spearman's rank correlation test).

Therapy. Though they may well play a part in limiting the infection in these children, antibiotics often fail to clear these children of established infecting organisms, particularly when they have abscesses and chronic pneumonia. However, in 2 patients (Cases 9 and 10) long periods of remission occurred while on antituberculous drugs for 2 and 7 years respectively, though both subsequently relapsed while still on such treatment.

Because of the suspicion that the defective polymorphonuclear leucocytes contribute to this persistence of infection, it was decided to attempt to destroy them with busulphan. Case 1 was critically ill when it was started. Continuous and recurrent infection in bones, liver, and lung had continued unabated from the 4th month of life, despite drainage and massive antibiotic cover. The effects of busulphan are shown in Fig. 2. The dose was increased from $0.08 \mathrm{mg} . / \mathrm{kg}$. per day to 0.25 $\mathrm{mg} . / \mathrm{kg}$. per day before the planned reduction of the neutrophil count to $1000 / \mathrm{cu}$. mm. was achieved. 


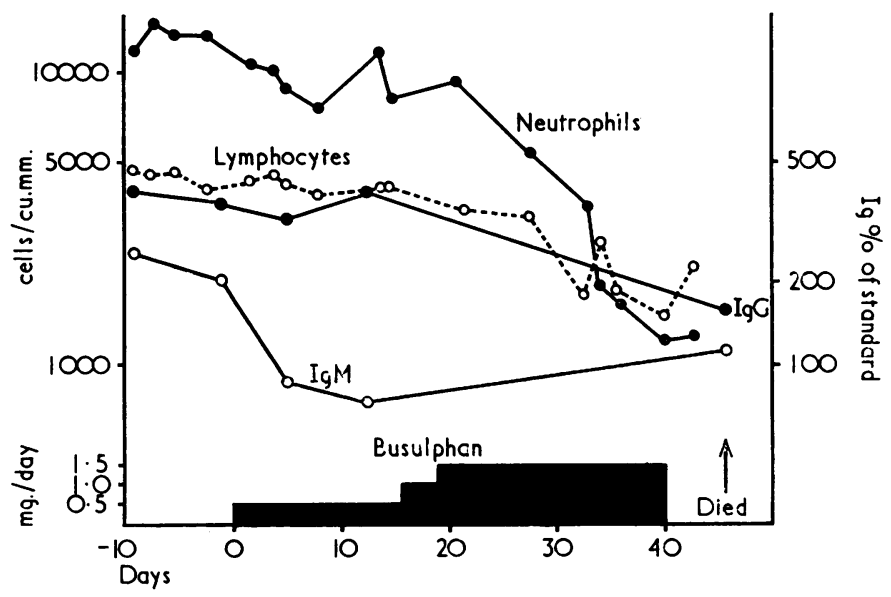

FIG. 2.-Busulphan treatment (mg./day) in a boy of 11 months with chronic granulomatous disease. Effect on blood cells and immunoglobulins.

After 37 days, oral erythromycin and intramuscular kanamycin were also given. No effect on his clinical status was noted and his many septic lesions continued. He died 5 days after busulphan was discontinued, during which a small increase in the neutrophil count occurred. Serial blood cultures during busulphan therapy were negative. Serial immunoglobulin levels (Fig. 2) showed a slight fall in IgG. At necropsy widespread chronic abscesses in liver, lung, and bone were found. Histological examination showed widespread evidence of infection, with areas of granulomatous reaction, but no evidence of a malignant process.

The other child treated (Case 3) was not so ill but had had 35 suppurative lymph node abscesses, occurring virtually continuously throughout the preceding 2 years, and liver and lung abscesses, in spite of antibiotic and surgical treatment. A satisfactory neutropenic effect was achieved on $0.15 \mathrm{mg}$. $/ \mathrm{kg}$. per day of busulphan given for 57 days (Fig. 3). Antibiotic therapy was started once neutropenia was achieved and continued for 3 weeks after busulphan had been discontinued. The suppurative lesions present at the start of therapy cleared, and he remained symptom free for 5 months after withdrawal of busulphan. Then a further cervical abscess occurred which was treated by surgery and antibiotics. This was followed by two more lymph node abscesses, and a second course of busulphan was given without antibiotic cover, which was again followed by complete remission. Marked cutaneous delayed hypersensitivity to avian tuberculin was noted of retesting, during the second period of busulphan induced neutropenia.

Treatment was started in another child (Case 2) but had to be withdrawn after 2 weeks because of a profound fall in the serum immunoglobilin levels; these, and the slight neutropenia, roseôt pretreatment levels after stopping the drug There was no detectable clinical effect.

Basic proteins of polymorphonuclear leuco cyte. The precise mechanism of failure of killin $\overrightarrow{\theta_{3}}$ certain bacteria following ingestion by the neutro 3

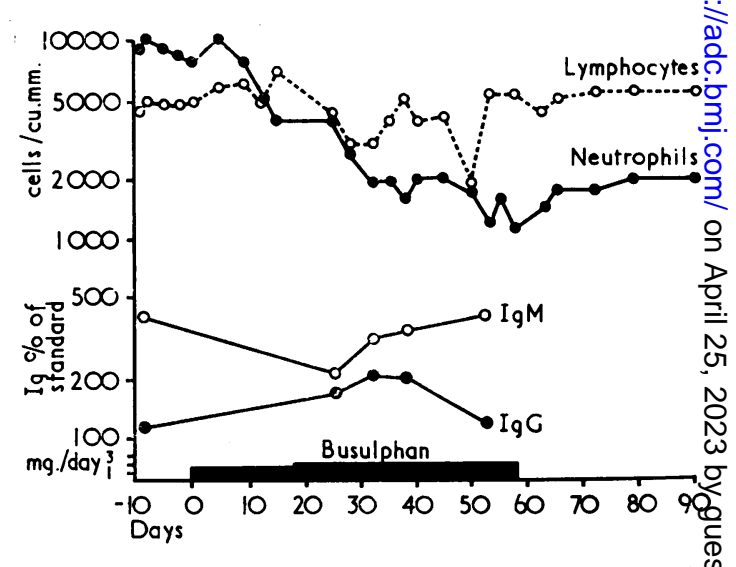

FIG. 3.-Busulphan treatment (mg./day) in a boy of $\frac{9}{7}$ years with chronic granulomatous disease, plotted as Fig. 20 
phil is not fully understood, but basic lysosomal proteins having some species specific bactericidal effect are known to occur (Zeya and Spitznagel, 1968).

Dr. A. C. Allison and Dr. A. Griffiths kindly studied these proteins qualitatively by electrophoresis in 3 of these patients; no gross abnormality was noted.

Studies in relatives. Detailed family histories were obtained from 6 of these 8 families of these 10 boys, and 150 members from three previous generations gave no suggestion of a similar illness except that the maternal great uncle of Cases 5 and 6 was said to have had repeated neck abscesses until the age of 10 years, but eventually outgrew this tendency; he died from a myocardial infarction at $\mathbf{4 0}$ years.

Polymorphonuclear leucocyte function was studied in sibs, parents, and 5 grandparents (Table II and Fig. 1). All the fathers were well with no history of undue susceptibility to infection, except the one who died from lymphatic leukaemia at 53 years. 2 of the 8 mothers had a persistent facial rash; in 1 (mother of Cases 7 and 8) this resembled discoid lupus erythematosus, in the other (Case 1) the rash was similar to that seen in the systemic lupus erythematosus. Neither had other evidence of SLE, and LE cells were not

TABLE II

Results in First Degrce Relatives

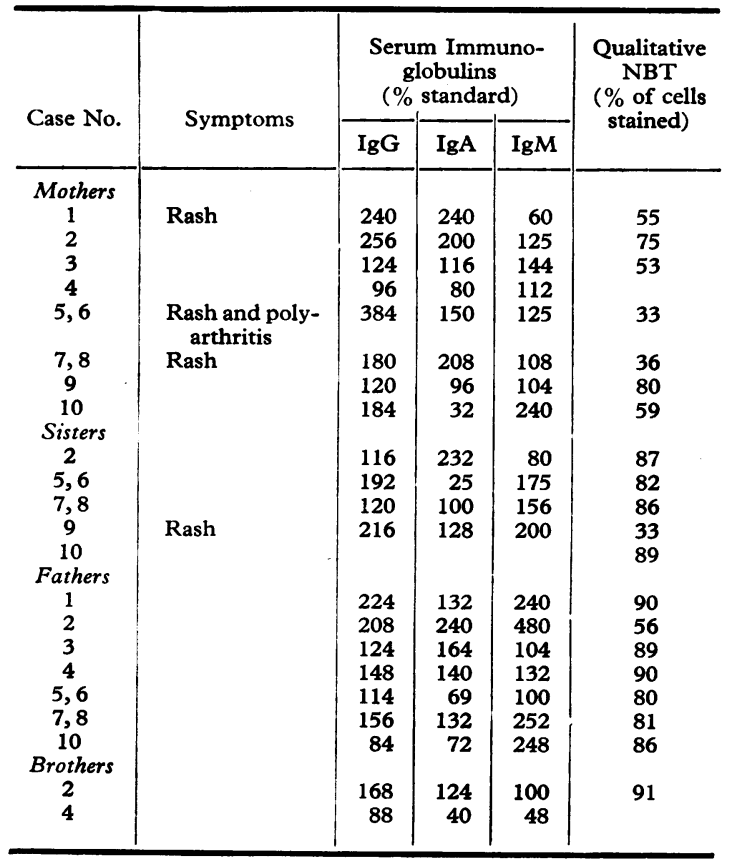

found in their blood. One other (mother of Cases 5 and 6) had an episode of polyarthritis lasting 9 months at 15 years of age; though the arthritis has not recurred she now has marked Raynaud's phenomenon. 6 of the 8 mothers gave values for the NBT test which were less than the control values (Fig. 1). These included the 3 with symptoms described above. The serum immunoglobulin levels were raised in 4,3 of whom had symptoms. The values for the NBT test in 2 clearly fell within the range of the controls. On this evidence they cannot be classified as differing from the other mothers, but one of these was highly discrepant in that her bacterial killing was grossly abnormal (Thompson et al., 1969). The values for the qualitative NBT test are lower in the symptomatic mothers than in the asymptomatic mothers (Table II), but the difference is not quite significant. Results of the quantitative NBT test in a larger series of partly affected female relatives of boys with chronic granulomatous disease (9 mothers, 1 sister, and 1 aunt) show a significant relation between the presence of lupus-like features and the quantitative NBT test results (Table III).

\section{TABLE III}

Results of the Quantitative NBT test $(\triangle O D)$ on 11 Female Relatives (9 mothers, 1 sister, and 1 aunt) of Boys with Chronic Granulomatous Disease, thought to be Heterozygous for Abnormal Gene

\begin{tabular}{c|c}
\hline Asymptomatic & Symptomatic \\
\hline 0.062 & 0.03 \\
0.08 & 0.047 \\
0.085 & 0.05 \\
0.10 & 0.06 \\
0.30 & 0.06 \\
& 0.085 \\
\hline
\end{tabular}

Rank sum test:- $p<0.05$.

All the fathers were clinically well with no undue history of infection, except for one who had died of leukaemia. Of the 7 who were studied by the qualitative nitro-blue tetrazolium reaction, 6 gave normal values, but the father of Case 2 gave an intermediate value, which was confirmed by the quantitative NBT test and the bactericidal test (Thompson et al., 1969), and these two more discriminating tests have shown that a larger series of fathers of boys with this disease, which included most of these, differs significantly from a control population (Chandra et al., 1969a). A paternal greatuncle of Cases 5 and 6 died of leukaemia.

Apart from 2 pairs of brothers studied (Cases 5 and 6 , and 7 and 8), 3 other brothers of these 
patients had died with an illness of a similar nature. Two brothers were asymptomatic, and one of these was normal to the qualitative NBT test (repeated 3 times). The twin brother of Case 4 had a value for both the quantitative and the bactericidal test, just within the normal range. This boy, like his affected twin brother, has rather low serum immunoglobulin levels.

Of the 5 sisters (no history of deaths), 4 were asymptomatic and were normal on qualitative NBT test, confirmed in 2 by the quantitative test, and the bactericidal test. The sister of Case 9 had a tendency to recurrent boils and had a chronic raised non-irritative rash on the dorsum of the feet. All the tests gave values in the intermediate range and the serum immunoglobulins were raised, similar to those obtained in the asymptomatic mothers (Table II).

\section{Discussion}

The clinical features in these patients are qualitatively similar to those already described but they showed a considerable range of severity of expression, from the very severe (Cases 1 and 2), in whom symptoms were continuous, resulting in death of one at 13 months, and marked chronic ill health in the other, to a very mild picture in another (Case 8), who had minor skin sepsis in the first year of life, and 2 episodes of pneumonia at 10 years, and Cases 9 and 10, who had no symptoms in early childhood and long periods of remission between infective episodes. This range led to an attempt to rank them in order of severity, and the significant correlation with the NBT results confirms the validity of this impression, and shows that it is related to the underlying defect. Of particular interest is the history of a maternal great-uncle (of Cases 5 and 6) who had recurrent cervical abscesses during the first 10 years of life but eventually outgrew the susceptibility to infections and died from myocardial infarction at 40 years. It is not possible to be sure that he had the same illness as these children, but the history is strongly suggestive. If so, he is clearly the most mildly affected patient yet described, and presents the possibility that there may be many such undetected. Perhaps, too, if these children survive early childhood, compensation is eventually achieved presumably by hypertrophy of other mechanisms such as the increase of immunoglobulin concentration, which leads to effective immunity in spite of the leucocyte defect. Therapy must be planned with these possibilities in mind.

The micro-organisms cultured from these patients are with certain additions consistent with previotas reports (Johnston and McMurry, 1967). Staph. aureus, Esch. coli, various moulds, and Serraita marcescens are characteristic. Streptococcus $p \overrightarrow{\text { Ped- }}$ genes and $H$. influenzae were conspicuously absegt. In this context, the degree of specificity of the bagic bactericidal proteins of polymorphonuclear leugescytes would be a possible explanation of this, bit a qualitative study of these showed no gross änormality in these patients. Aspergillus nidulams (grown repeatedly from Case 2, whose seru值 contained precipitating antibodies to it) is not usually regarded as a human pathogen. Casecut lived in Singapore and developed lesions due $\$ 50$ Pseudomonas pseudomallei, a widespread inhabitast of surface water in that area (Thin, 1968). Acitfast organisms were seen in the pus of Cases 2 and 3 , and they had delayed hypersensitivity to avit tuberculin. Case 10 had chronic discharging sinuses, and on one occasion Actinomyces israeftii was cultured. The findings of such unustal pathogens in such a high proportion of patients with a severe deficiency of a non-specific immunfy mechanism must lead to the suspicion of such a defect whenever such organisms are found to causing an infection. The possibility must also be considered in all such patients that the seyese and chronic process is not necessarily a property of the organism but of the host. With more pathogens, the relevance of infecting dose ss indicated by the second wave of symptoms in Cas 58 after years of good health, which coincided wh a liver abscess in his brother, treated initially home. The reaction of the physicians and surgeons to the problem presented by these children, whon these rare organisms were cultured, is interesting. Concern, arising from the uncertainty which they felt in view of the persistent illness of the children was sometimes lulled if an unusual organism cultured, as they were inclined to ascribe the symdrome to an effect of this unusual organism. $\exists$ t is not normal for a child to be infected with moulegs, Actinomyces israelii or Pseudomonas pseudomaliei, in the sense that it is normal to have measles, and the role of the host as well as the parasite must be considered in any syndrome of infection.

An X-linked mode of inheritance has been post lated, based on the occurrence of the full expression of the syndrome in male sibs and cousins, and the demonstration of a partial leucocyte abnormalaty in mothers, which has been interpreted as suggestive of mosaicism, a possible example of Lyon's effect (Windhorst et al., 1967; 1968). However, recent reports of this disease in girls suggest that an alternative mode of inheritance is also possibue 
(Baehner and Nathan, 1968; Quie et al., 1968). The parents of these girls (first cousins in one family) were normal on the NBT test and bactericidal capacity.

Studies on the fathers of the patients described in this report using a quantitative NBT test, and a more discriminating bactericidal test (Chandra, Cope, and Soothill, 1969b) have shown that they, too, are abnormal, though not as abnormal as the mothers (Chandra et al., 1969a). This has led to the hypothesis that the inheritance is an autosomal recessive, with sex modification. The detection of gross abnormality in all these tests in the father of Case 2, disproving the hypothesis that intermediate values of the qualitative NBT test provide evidence of mosaicism, and the evidence of abnormal bacterial killing with normal NBT tests in the mother have already been reported (Thompson et al., 1969).

The incidence of skin rashes which had some resemblance to lupus in four of the mothers and one sister is of interest; two isolated examples of this association have been previously reported (Landing and Shirkey, 1957; MacFarlane, Speirs, and Sommerville, 1967). The relation between this and the result of the NBT test confirms the significance of the association. One of the mothers had arthritis and severe Raynaud's phenomenon which are also possible features of disseminated lupus erythematosus, and they had raised immunoglobulin concentrations, as did the father of Case 2, who had NBT and bacterial killing tests comparable with the mothers, though he was otherwise asymptomatic. Perhaps the partial leucocyte defect in these mothers leads to repeated antigenic stimulus from abnormal survival of phagocytosed organisms leading to the raised immunoglobulins. This could also give rise to continued release of endotoxins, having an adjuvant effect, in association with antigens from damaged host cells which could result in induction of auto-allergy. It is attractive to suggest that this may be the pathogenesis of the lupus-like illness they have, though LE cells and antinuclear factor were negative when tested. Presumably the patients themselves do not live long enough for this effect to develop in them. The fathers, also partly affected, though less severely than the mothers (Chandra et al., 1969a), do not show these abnormalities, but their tests are similar to those of the asymptomatic mothers. Two members of these families died of leukaemiathe father of Case 9, and the paternal uncle of the mother of Cases 5 and 6 . This incidence is greater than would be expected, but may, of course, have occurred by chance. If, however, we are right in regarding this disease as having an autosomal recessive inheritance, the possibility arises that the leukaemia may also have resulted from such longterm stimulus to cell proliferation.

Long-term chemotherapy may be helpful in these children, but may also have contributed to the high incidence of fungal infection. It may be, particularly in the less severely affected subjects, that periods free of infection can be attained in this way. The impression remains, however, that once an infection, protected as it is in abnormal cells, is established, it becomes difficult to eradicate. Therefore, the possibility of producing a remission may be aided by inducing a period of neutropenia, so that specific immunity mechanisms and antibiotics can achieve clearance of the infection. We attempted this in 3 patients, and are cautiously encouraged by our findings in Case 3. Case 1 was desperately ill at the start of busulphan therapy, so the failure to produce detectable benefit to him does not discourage us from further trials. Case 2 was also desperately ill, and, because the immunoglobulin concentration was depressed while on busulphan treatment, we stopped treatment before the intended level of neutrophils was achieved. This form of therapy can only be expected to have temporary effect and we feel its possible indication is in repeated infective lesions due to the same organisms with continued recurrence in spite of adequate surgery and antibiotics. The compensating leucocytosis secondary to the infection may well be a contributory factor in maintaining the chronicity of the episode.

We are grateful to our colleagues in this and other hospitals for permission to study their patients and quote their observations, to Dr. J. A. Dudgeon for advice, and for the microbiological data, to the Medical Research Council for support to the M. R. C. Research Group in Immunology, and to the Joint Research Board of The Hospital for Sick Children and Institute of Child Health for support to one of us (ENT).

\section{REFERENCES}

Baehner, R. L., and Nathan, D. G. (1967). Leukocyte oxidase. Science, 155, 835.

$\longrightarrow$, and - (1968). Quantitative nitroblue tetrazolium test in chronic granulomatous disease. New England fournal of Medicine, 278, 971.

Berendes, H., Bridges, R. A., and Good, R. A. (1957). A fatal granulomatosus of childhood: the clinical study of a new syndrome. Minnesota Medicine, 40, 309.

Bridges, R. A., Berendes, H., and Good, R. A. (1959). A fatal granulomatous disease of childhood: the clinical, pathological, and laboratory features of a new syndrome. American fournal of Diseases of Children, 97, 387.

Carson, M. J., Chadwick, D. L., Brubaker, C. A., Cleland, R. S., and Landing, B. H. (1965). Thirteen boys with progressive septic granulomatosis. Pediatrics. 35, 405.

Chandra, R. K., Cope, W. A., and Soothill, J. F. (1969a). Chronic granulomatous disease: evidence for an autosomal mode of inheritance. Lancet, $2,71$. 
- - $\longrightarrow$, and - (1969b). Chronic granulomatous diseasea sensitive bactericidal nephelometric method for detection of patients and carriers. To be published.

Evans, P. (1962). Disseminated granulomata. Proceedings of the Royal Society of Medicine, 55, 982.

Holmes, B., Quie, P. G., Windhorst, D. B., and Good, R. A. (1966). Fatal granulomatous disease of childhood. An inborn abnormality of phagocytic function. Lancet, 1, 1225.

Johnston, R. B., Jr., and McMurry, J. S. (1967). Chronic familial granulomatosis. Report of 5 cases and review of the literature. American fournal of Diseases of Children, 114, 370.

Landing, B. H., and Shirkey, H. S. (1957). A syndrome of recurrent infection and infiltration of viscera by pigmented lipid histiocytes. Pediatrics, 20, 431.

MacFarlane, P. S., Speirs, A. L., and Sommerville, R. G. (1967). Fatal granulomatous disease of childhood and benign lymphocytic infiltration of the skin (congenital dysphagocytosis). Lancet, 1, 408.

Mancini, G., Carbonara, A. O., and Heremans, J. F. (1965) Immunochemical quantitation of antigens by single radial immunodiffusion. International fournal of Immunochemistry, $2,235$.

Quie, P. G., Kaplan, E. L., Page, A. R., Gruskay, F. L., and Malawista, S. E. (1968). Defective polymorphonuclearleukocyte function and chronic granulomatous disease in two female children. New England fournal of Medicine, 278, 976.
—, White, J. G., Holmes, B., and Good, R. A. (1967). In vite bactericidal capacity of human polymorphonuclear leukocyes: diminished activity in chronic granulomatous disease of ch fahood. Fournal of Clinical Investigation, 46, 668.

Thin, R. N. T. (1968). Melioidosis. M.D. Thesis. Univer茫y of Edinburgh.

of Edinburgh.
Thompson, E. N., Chandra, R. K., Cope, W. A., and Soothill, $\frac{\text { S }}{\text { F. }}$. (1969). Leucocyte abnormality in both parents of a patien with chronic granulomatous disease. Lancet, 1, 799.

Windhorst, D. B., Holmes, B., and Good, R. A. (1967). A ne画y defined $X$-linked trait in man with demonstration of the $L$ \%on effect in carrier females. ibid, 1, 737.

—_, Page, A. R., Holmes, B., Quie, P. G., and Good, R. A. (1968), The pattern of genetic transmission of the leucocyte defectsin fatal granulomatous disease of childhood. Fournal of Clinietal Investigation, 47, 1026.

Zeya, H. I., and Spitznagel, J. K. (1968). Arginine-rich proteins of polymorphonuclear leukocyte lysosomes. Fournal $\overrightarrow{\omega_{S}}$ Experimental Medicine, 127, 927.

Correspondence to Professer J. F. Soothill, Depaụtment of Immunology, Institute of Child Health, 30 Guilford St., London W.C.1. 